JPE 10-1-8

\title{
Harmonic Intensity Reduction Technique for Single Phase Switched Reluctance Motor Drives Using a New Random PWM Scheme
}

\author{
Minh-Khai Nguyen*, Young-Gook Jung**, Hyong-Yeol Yang ${ }^{\dagger}$, and Young-Cheol Lim* \\ * Dept. of Electrical Engineering, Chonnam National University, Gwangju, Korea \\ ** Dept. of Electrical Engineering, Daebul University, Chonnam, Korea \\ $\dagger$ Dept. of Electrical Engineering, Honam University, Gwangju, Korea
}

\begin{abstract}
This paper proposes a new random switching strategy using a DSP TMS320F2812 to reduce the harmonics spectra of single phase switched reluctance motors. The proposed method combines the random turn-on/off angle technique and the random pulse width modulation technique. A harmonic spread factor (HSF) is used to evaluate the random modulation scheme. In order to confirm the effectiveness of the proposed method an experiment was conducted. The experimental results show that the harmonic intensity of the output voltage for the proposed method is better than that for conventional methods.
\end{abstract}

Key Words: HSF (Harmonic spread factor), Random PWM scheme, Single phase 6/6 SRM

\section{INTRODUCTION}

Switched reluctance machines (SRMs), because of their simple construction and low manufacturing cost, are gaining importance in consideration for automotive applications. The inherent nature of an SRM is both rugged and fault tolerant. Recently, SRMs have been considered as a propulsion motor in electric and hybrid vehicle applications due to their high efficiency, high reliability and robustness in operation [1]-[3]. However, there are several disadvantages to these machines. The primary disadvantages of an SRM are the emitted acoustic noise, the higher torque ripple and the vibration when compared to other motors. The emitted acoustic noise in SRMs is due to triggering mechanical resonances. It has been shown that the dominant source of vibration and acoustic noise in an SRM is the radial vibration of the stator [4]. These vibrations are caused by a radial magnetic force, which acts to decrease the gap separation between the rotor and the stator as their poles approach alignment.

Recently, several papers have been presented to characterize SRM acoustic noise as shown in [5-10]. Unfortunately, only a few control approaches have been presented to lower SRM acoustic noise. The presented method in [5] is to randomly vary the turn-on/off angle within $1^{\circ}-3^{\circ}$ which is useful in

\footnotetext{
Manuscript received Feb. 9, 2009; revised Oct. 23, 2009

$\dagger$ Corresponding Author: sfish2000@gmail.com

Tel: +82-62-940-5498, Fax: +82-62-940-5072, , Honam University

Dept. of Electrical Engineering, Honam University, Korea

* Dept. of Electrical Engineering, Chonnam National University, Korea

** Dept. of Electrical Engineering, Daebul University, Korea
}

the whole operating area of an SRM. However, this method only gives a small reduction in the acoustic noise emission. Another method is to use a switching frequency higher than 18 $\mathrm{kHz}$. However, it has the drawback of high switching losses in power inverters. A recent method to reduce acoustic noise is to use the random pulse width modulation (PWM) technique that is useful for induction motors [11]-[13]. This random PWM scheme based on the use of random number generation has been proposed for comparison with the fundamental sinusoidal waveform in order to generate a random PWM waveform. Recent reports as shown in [11-13] have confirmed that the random pulse width modulation (RPWM) approach offers advantages such as reduced radio interference from converter equipment and improved acoustic and vibration effects in electronic drive systems.

In this paper, we propose a simple and effective method using the random modulated strategy and the random PWM technique for a 6/6 SRM. This technique plays an essential role in a significant reduction of acoustic noise by combining the varying turn-on/off angle and the random PWM scheme. While the aim of the random turn-on/off angle technique is to decrease the amplitude of the fundamental harmonics, the random PWM technique is used to provide harmonic spectra intensity that is flatter than that obtained by conventional methods. This combination will help avoid triggering mechanical resonances. Thus, the harmonic spectra of the output voltage in an SRM are reduced significantly. The experimental results obtained from a laboratory system show that the harmonic intensity of the output voltage for the proposed method is 


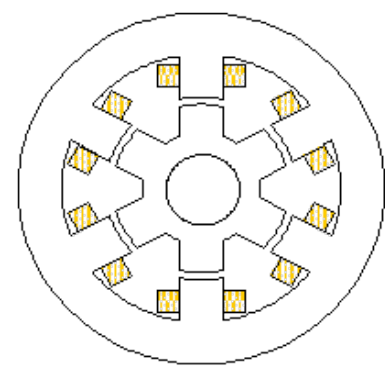

(a)

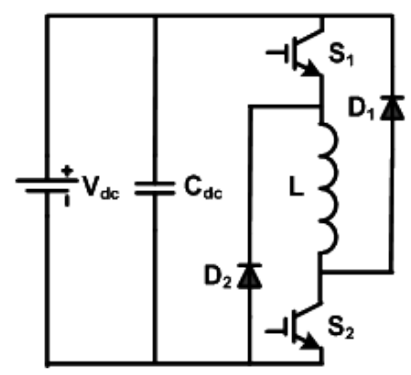

(b)
Fig. 1. Single phase 6/6 SRM. (a) Cross-section profile; (b) Converter topology.

better than that for conventional methods.

\section{The Single Phase 6/6 SRM Structure}

In a single phase asymmetric bridge exciting power converter, there are two main switches and two flywheel diodes in each phase circuit. Fig. 1 shows the cross section profile and converter topology used for the drive, respectively. An elementary equivalent circuit for SRMs can be derived neglecting the mutual inductance between the phases as follows. The voltage across the phase winding is equal to the sum of the resistive voltage drop and the rate of the flux linkages and is given by [1]:

$$
v=R_{s} i+\frac{d \lambda(\theta, i)}{d t}
$$

where $v$ is the phase voltage, $i$ is the current, $R_{s}$ is the phase resistance and $\lambda$ is the flux linkage given by:

$$
\lambda=L(\theta, i) i
$$

where $L$ is the phase inductance dependent on the rotor position and phase current. The phase voltage equation is then:

$$
v=R_{s} i+L(\theta, i) \frac{d i}{d t}+\frac{d L(\theta, i)}{d \theta} \omega_{m} i
$$

where $\omega_{m}$ is the rotor angular velocity and $\theta$ is the rotor position.

The instantaneous electric power which is a product of the phase voltage and current is as follows:

$$
p=v i=R_{s} i^{2}+L(\theta, i) i \frac{d i}{d t}+i^{2} \frac{d L(\theta, i)}{d t}
$$

The instantaneous electro-magnetic torque is given by the following equations:

$$
T=\frac{1}{2} i^{2} \frac{d L(\theta, i)}{d \theta}
$$

\section{Conventional and Proposed Methods}

In an SRM the turn-on angle $\alpha_{o n}$ and turn-off angle $\alpha_{\text {off }}$ can be controlled as well as the duty-cycle D [5]. The dutycycle is normally controlled at a low speed in order to reduce the current flow in the SRM. At higher speeds the current is limited by the back-emf and there is no need to use different duty-cycles. Instead the turn-on/off angle is controlled. Several

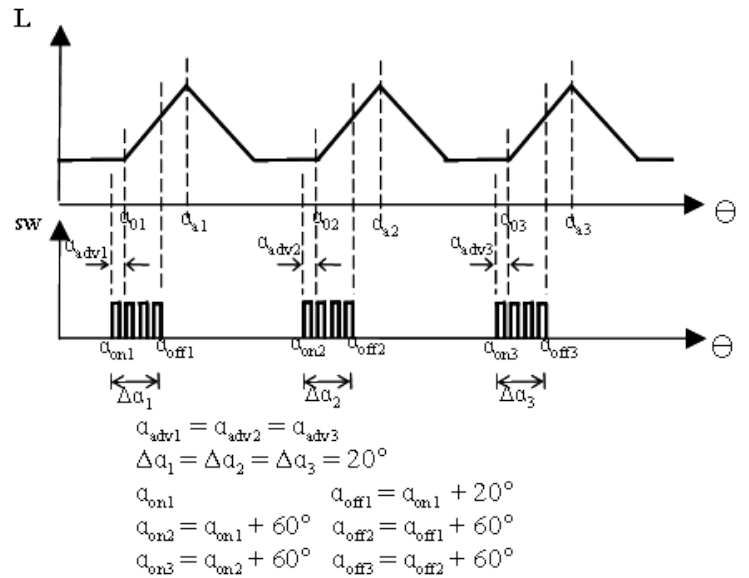

Fig. 2. Conventional method with chopping mode.

methods have been proposed to reduce the acoustic noise in SRMs by the modulation technique. The first method is to vary the switching frequency randomly. The second one is to change between lagging edge and leading edge modulation. The other method is to randomly vary the turn-on angle $\alpha_{\text {on }}$ and the turn-off angle $\alpha_{\text {off }}$ within $1^{\circ}-3^{\circ}$ as shown in [5]. However, these methods only give a small reduction in the acoustic noise emission.

The proposed method is a combination of the random PWM scheme and varying the turn-on/off angle. This combination will help avoid triggering mechanical resonances. As a result, the acoustic noise in an SRM will be reduced significantly. In this section, PWM strategies are shown and discussed for various methods.

\section{A. Conventional Methods}

The conventional method, as shown in Fig. 2, is using the PWM technique with a fixed turn-on/off angle. In Fig. 2 the angle $\alpha_{0}$ is the angle where the rotor and stator pole start overlapping physically; $\alpha_{a}$ is the aligned angle where the rotor is totally overlapped by the stator; $\alpha_{a d v}$ is the advance angle ( $\alpha_{a d v}$ is negative if $\alpha_{o n}$ is smaller than $\alpha_{0}$ and conversely $\alpha_{a d v}$ is positive and $\Delta \alpha_{i}\{i=1,2,3\}$ is the total conduction angle). $\alpha=0^{\circ}$ is when the rotor and stator are completely unaligned. This is the conventional control method for SRMs. Its disadvantages are the emitted acoustic noise and the higher torque ripple.

Another method that can reduce acoustic noise is shown in Fig. 3. This method employs the random PWM technique while the turn-on/off angles are fixed. This technique is useful for induction motors to reduce acoustic noise [11]-[13].

\section{B. Proposed Method}

The proposed method is a combination of the random PWM technique and a varying of the turn-on/off angle.

The random strategy is used to vary the turn-on angle $\alpha_{o n}$ and turn-off angle $\alpha_{\text {off }}$ randomly according to $\alpha_{0}$ and $\alpha_{a}$ within $\Delta \alpha_{r}=2^{\circ}$ while $\Delta \alpha_{i}(i=1,2,3)$ is kept constant. $\Delta \alpha_{r}$ is an interval for turn-on/off angle control. The basic 


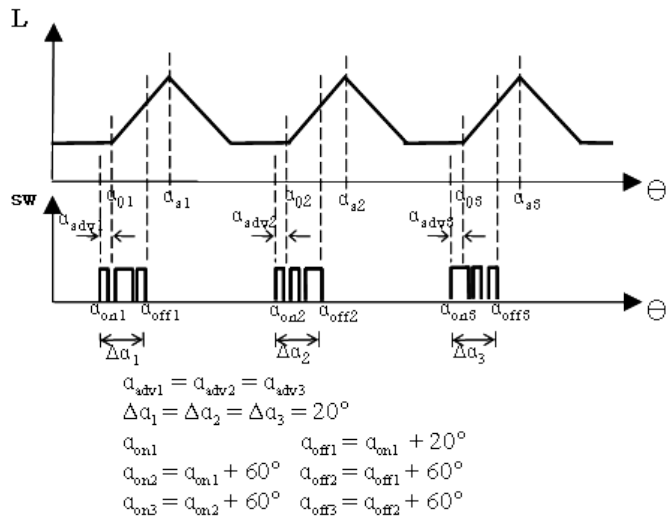

Fig. 3. Conventional method with RPWM technique.

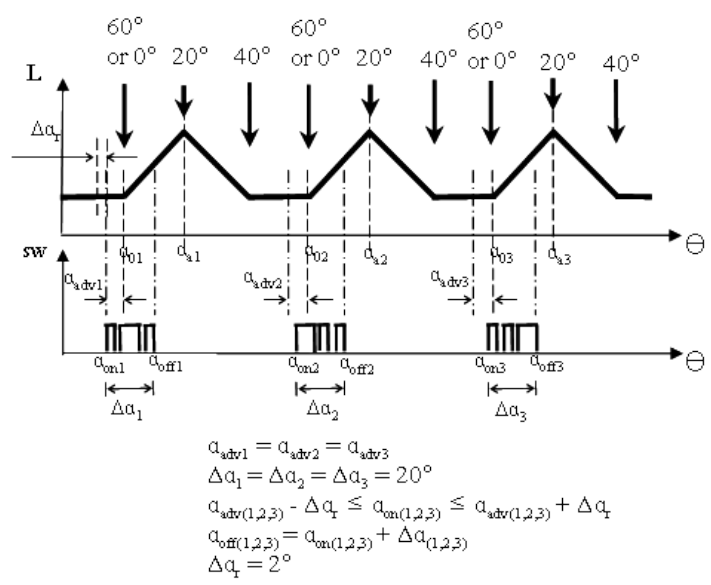

Fig. 4. Proposed method.

principle of the strategy is shown in Fig. 4. In this case, $\alpha_{o n}$ is not the same as $\alpha_{a d v}$ but varies according to $\Delta \alpha_{r}$ while they are the same angle in the conventional method. Fig. 5 shows practical cases for the combination of random turn-on angle $\alpha_{\text {on }}$, turn-off angle $\alpha_{\text {off }}$ and RPWM. In Fig. 5, modes $1,2,3$ and 4 are practical cases for the proposed method; $r j$ $(j=1,2,3,4)$ is the random angle which is the difference between $\alpha_{a d v}$ and $\alpha_{o n}$ while its absolute value is within the range from $0^{\circ}$ to $2^{\circ}$. The advantage of this new method is to reduce acoustic noise significantly.

A random number is generated by a linear congruential generator (LCG) algorithm [12] using the random pulse position (RPP) scheme. A positive integer random number $f_{\text {ran }}$ within the range $\left[0, i_{m}\right]$ can be generated by:

$$
f_{\text {ran }+1}=\left(f_{\text {ran }} \cdot i_{a}+i_{c}\right) \% i_{m}
$$

And a floating point random number ran in the range from 0 to 1 is generated by:

$$
\text { ran }=(\text { float }) f_{\text {ran }} /(\text { float }) i_{m}
$$

In (6)-(7), $i_{a}, i_{c}$ and $i_{m}$ are the selected coefficients. They are the multiplier, the increment and the modulus, respectively.

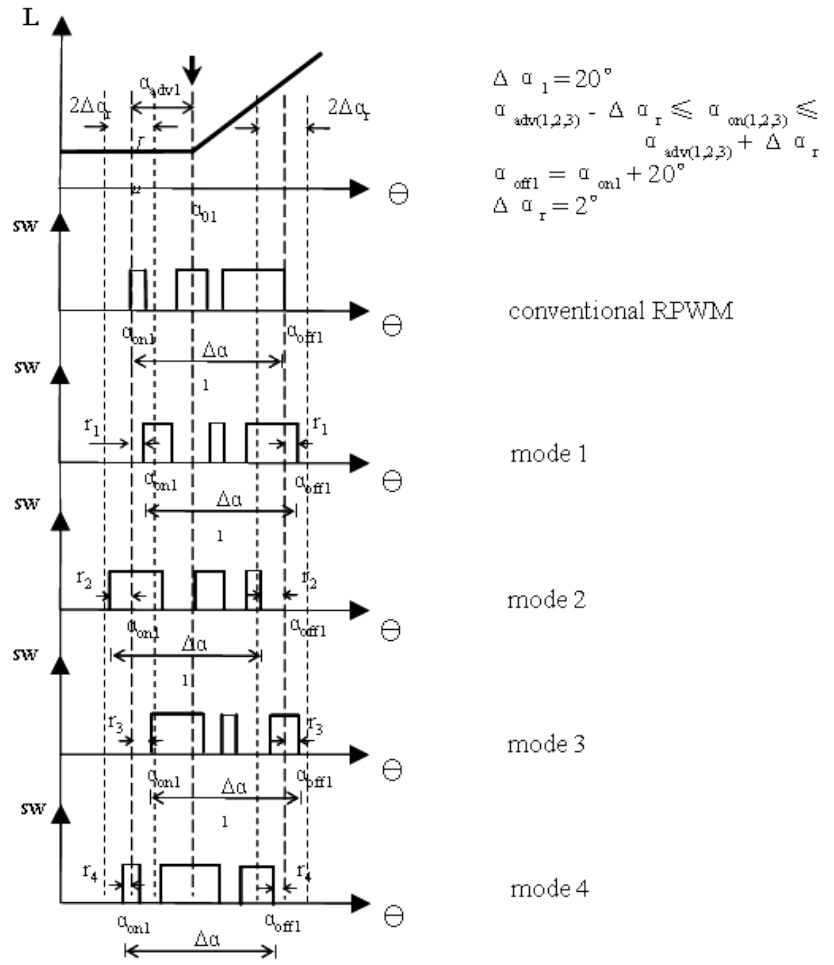

Fig. 5. Practical cases for combination of random the turn-on/off angle and RPWM.

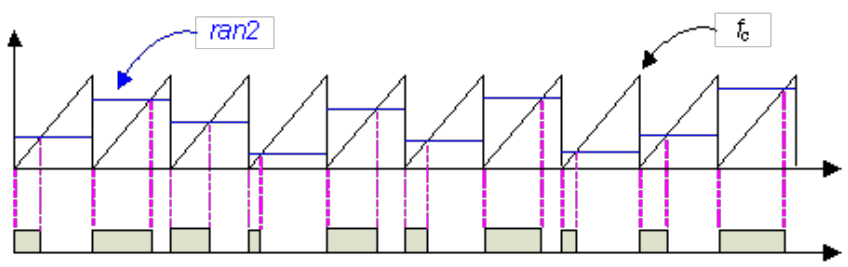

Fig. 6. Procedure of RPP generation.

The control system requires two separate random number generators: $\mathrm{ran} 1$ and $\mathrm{ran} 2$. ranl is used to generate the random turn-on angle while ran2 is used to generate the random PWM. Fig. 6 shows the procedure for random pulse position (RPP) generation. An asymmetric carrier $\left(f_{c}\right)$ with an amplitude of 1 at $6 \mathrm{kHz}$ is used to compare with a ran2 value from 0 to 1 .

\section{EXPERIMENTAL SETUP}

Fig. 7 shows the block of an SRM drive system. As shown in Fig. 7, the rotor position $\theta$ is calculated by the encoder through the rotor position calculation block; ran1 and ran2 are generated by the random number generator block. A fully digital PI current regulator is implemented for regulating the phase current of the SRM [14], [15]. The selection of the PI gains is a trade off between the minimum and maximum incremental inductance in one electrical cycle. Large PI gains have good performance with a large incremental inductance. However, they may reach a point in the electrical cycle where the system is not stable due to a small incremental inductance. The PI gains have to be selected so that there is a good balance in current regulation during the entire electrical cycle. The resulting overshoot is partially due to the response 


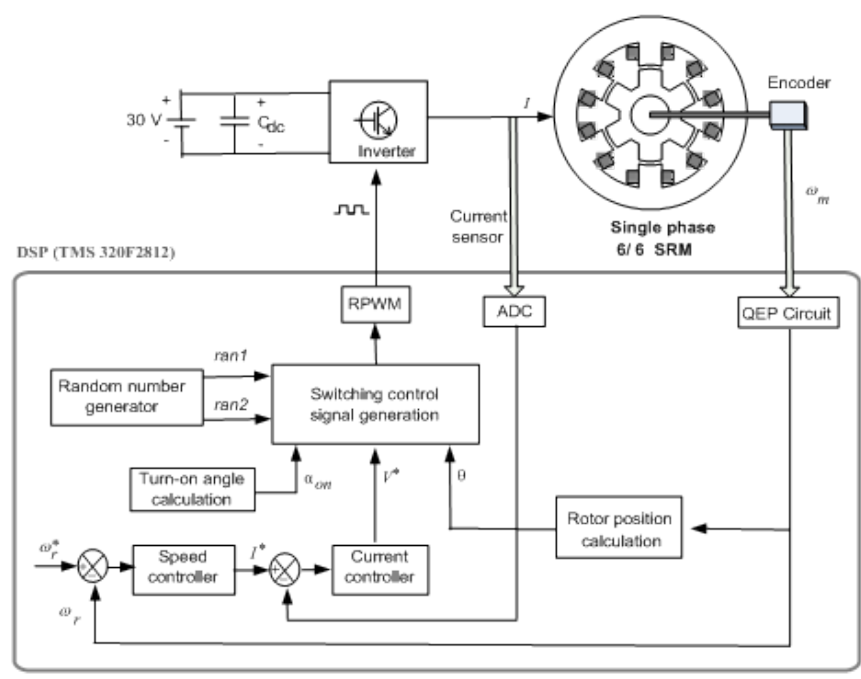

Fig. 7. Block diagram of the SRM drive system.

characteristics of a PI regulation to a step command. As a note; an improvement in performance could be obtained through gain scheduling and feedforward control concepts.

The switching control signal generation block controls the turn-on/off angle randomly. The flowchart of this random turnon/off angle control program is shown in Fig. 8. As shown in Fig. 8, the angle $\Delta \alpha_{r}$ is a constant that is chosen for the best performance operation of the system. The turn-on angle $\alpha_{o n}$ is calculated by the input values $\alpha_{a d v}, \Delta \alpha_{r}$ and ranl so as to guarantee the turn-on angle is triggered in the interval $\left[\alpha_{a d v}-\Delta \alpha_{r}, \alpha_{a d v}+\Delta \alpha_{r}\right]$. This value is compared with the rotor position to trigger on the IGBT gates $S_{1}$ and $S_{2}$. If the $\theta \geq 60-\alpha_{o n}$, flag is set and switches $S_{1}$ and $S_{2}$ are turned on, that is the turn-on angle position. After that, $S_{1}$ and $S_{2}$ are turned on/off according to the random PWM scheme until $\theta=20+\alpha_{o n}$. Then, when the $\theta \geq 20-\alpha_{\text {on }}$, flag is reset and $S_{1}$ and $S_{2}$ are turned off, the turn-off angle is set based on the following formula:

$$
\alpha_{\text {off }}=\alpha_{o n}+20^{\circ}
$$

\section{EXPERIMENTAL RESUlTS AND Discussion}

In this section, the experimental results are presented and compared to the various strategies. The overall experimental system is illustrated in Fig. 7. It includes a TMS320F2812 DSP controller, a DC bus voltage, a voltage source IGBT inverter and the single-phase 6/6 SRM as shown in Fig. 9. The inverter has two IGBT type power transistors and two power diodes. The input signals of the inverter are PWM signals from the DSP chip. The DC bus voltage is $30 \mathrm{~V}$; the interval $\Delta \alpha_{r}$ is 2 degrees; and the switching frequency $\left(f_{s w}\right)$ is $6 \mathrm{kHz}$. The parameters for the experimental conditions are listed in Table 1. In Fig. 7, the current control scheme, the speed control scheme, the random PWM generation, the A/D conversions, the coordinate transformation, the QEP detection and the random number generation are all realized with the software in the DSP chip. The experimental results show that a combination of the random turn-on/off angle technique with

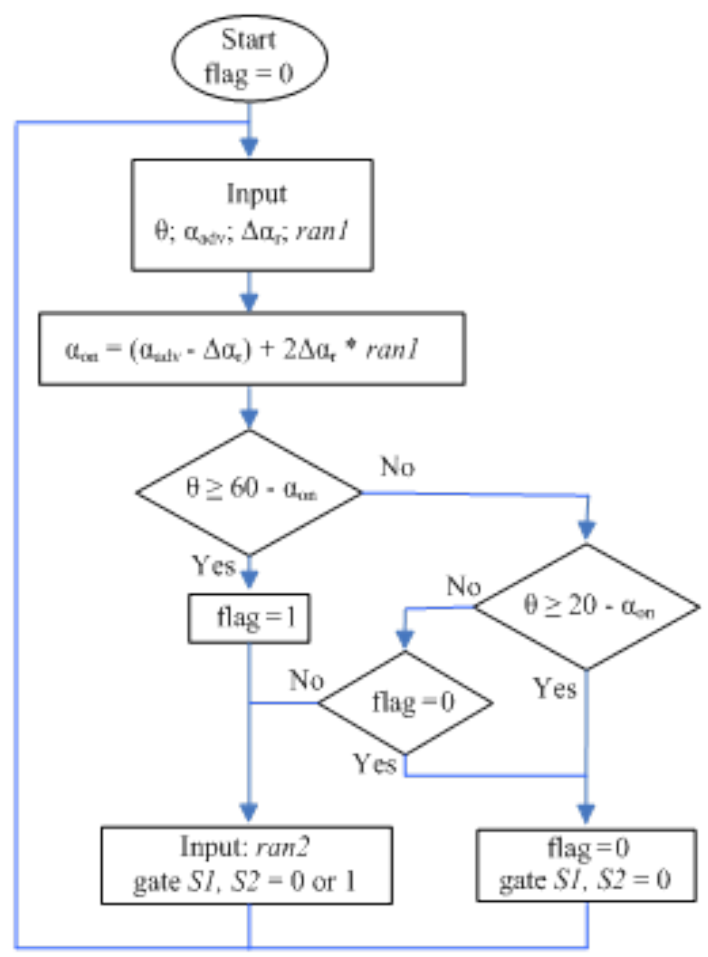

Fig. 8. Flowchart of random turn-on/off angle control program.

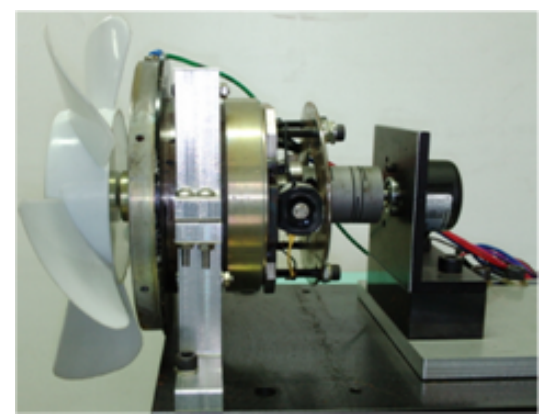

Fig. 9. Single-phase 6/6 SRM for experiment

the random PWM technique reduces the harmonics spectra significantly.

Fig. 10 shows the experimental results for the motor voltage waveform and the motor current waveform at a switching frequency $\left(f_{s w}\right)$ of $6 \mathrm{kHz}$ for each method. To fully explore the merits of the new method, Fig. 11 shows the power spectra of the motor voltage. As shown in Fig. 11a, for the conventional method, the amplitude of all the components is more dominant than that shown in Fig. 11c for the proposed method. The subharmonics in area (a) of Fig. 11c are smaller than those of Fig. 11a and 11b. In addition, in Fig. 11c for the proposed method, the dominant components in area (b) are more flat than those obtained by the conventional method.

For evaluating the random PWM technique, a simple indicator of the quality of the voltage spectra would be useful. For this purpose, the concept of statistical deviation can be employed and the harmonics spread factor (HSF) [12], [16] is defined as: 


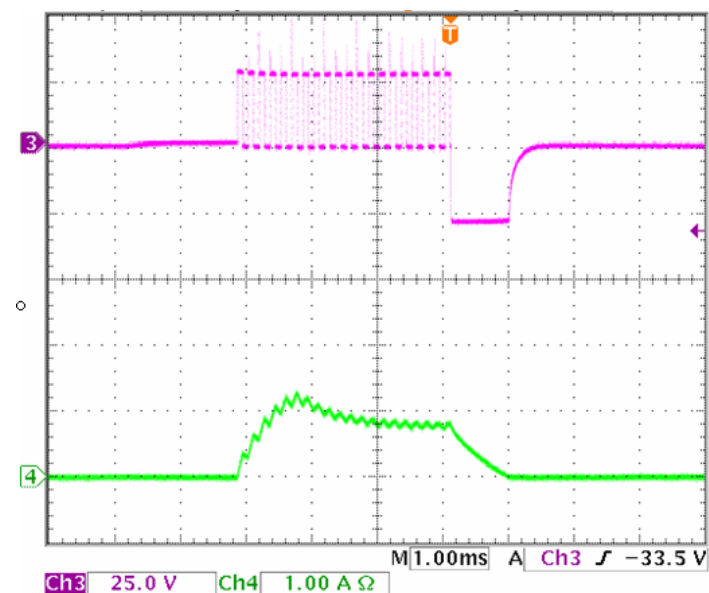

(a) Conventional method with chopping mode

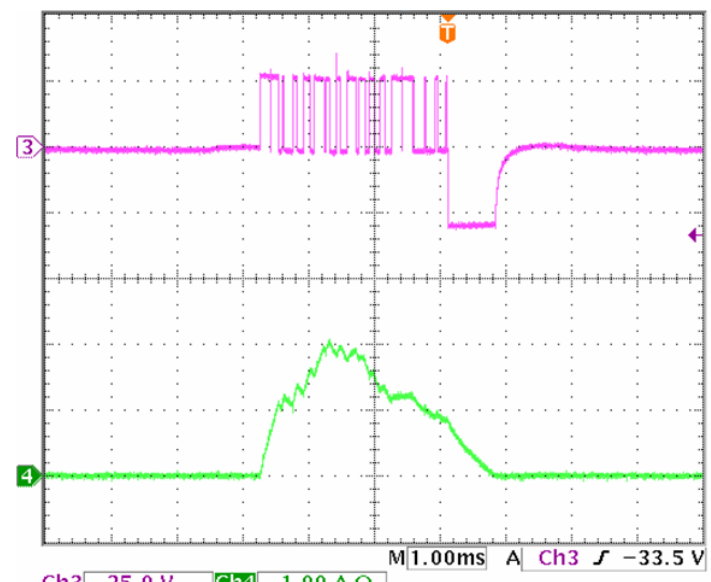

(b) Conventional method with RPWM technique

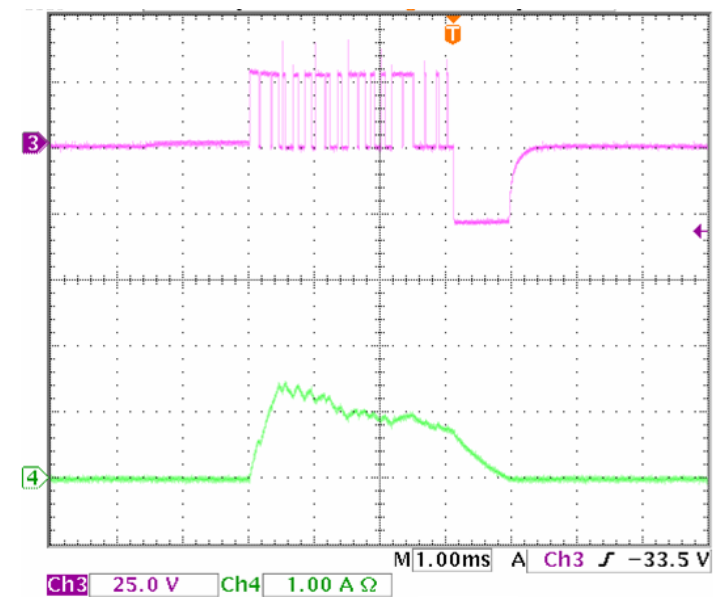

(c) Proposed method

Fig. 10. Measured output voltage and current at $1000 \mathrm{rpm}$. Voltage (top): 25V/div.; Current (bottom): 1A/div.

$$
H S F=\sqrt{\frac{1}{N} \sum_{j>1}^{N}\left(H_{j}-H_{0}\right)^{2}}
$$

where $N$ denotes the total number of frequency components considered, $H_{j}$ is the amplitude of the $j^{\text {th }}$ component and $H_{0}$ is the average value of all components given by:
TABLE I

SRM PARAMETERS FOR EXPERIMENTAL CONDITION

\begin{tabular}{|c|c|c|}
\hline \multicolumn{2}{|r|}{ Parameter } & Value \\
\hline \multicolumn{2}{|c|}{ DC bus voltage } & $30[\mathrm{~V}]$ \\
\hline \multicolumn{2}{|c|}{ PWM Switching frequency } & $6[\mathrm{kHz}]$ \\
\hline \multicolumn{2}{|c|}{$\Delta \alpha_{r}$} & 2 [degree] \\
\hline \multirow{6}{*}{ SRM } & Stack Length & $34[\mathrm{~mm}]$ \\
\hline & Diameter of Stator & $100[\mathrm{~mm}]$ \\
\hline & Diameter of Rotor & $54[\mathrm{~mm}]$ \\
\hline & No. of Stator Pole & 6 \\
\hline & No. of Rotor Pole & 6 \\
\hline & Air Gap & $0.3[\mathrm{~mm}]$ \\
\hline
\end{tabular}

TABLE II

COMPARISONS OF HSF FOR VARIOUS PWM SCHEMES

\begin{tabular}{|c|c|c|c|}
\hline $\begin{array}{c}\text { PWM } \\
\text { types }\end{array}$ & $\begin{array}{c}\text { Fixed } \\
\text { chopping } \\
\text { mode }\end{array}$ & $\begin{array}{c}\text { Conventional } \\
\text { RPWM }\end{array}$ & $\begin{array}{c}\text { Proposed } \\
\text { method } \\
\left(\Delta \alpha_{r}=2^{\circ}\right)\end{array}$ \\
\hline HSF [\%] & 40.03 & 18.31 & 16.29 \\
\hline
\end{tabular}

$$
H_{0}=\frac{1}{N} \sum_{j>1}^{N} H_{j}
$$

The HSF quantifies the spread spectra effect of the random PWM scheme and it should be small. For ideally flat spectra of white noise, the HSF would be zero. Table 2 gives the output voltage HSF for various PWM schemes. The HSF of the proposed method reaches $16.29 \%$ which is lower than those of the conventional methods $(18.31 \%)$. The random PWM control and the random turn-on/off angle control in the proposed method can be easily combined with the C-language program. Therefore, a two percent HSF improvement is quite worthwhile for the additional efforts. For the proposed method, Table 3 gives the output voltage HSF for various $\Delta \alpha_{r}$. As shown in Table 3 , the angle $\Delta \alpha_{r}=2^{\circ}$ is the best performance operation system because it archives a lower HSF value.

Fig. 12 shows the voltage spectra in the whole operation area of the 6/6 SRM for different switching frequencies. In comparing these results, we can observe that harmonic spectra are reduced significantly when using random modulation. It is clear that, as expected, the proposed strategy results in a significant improvement in acoustic noise reduction relative to other strategies.

\section{CONCLUSIONS}

This paper has discussed the implementation techniques for various random PWM and random turn-on/off angle strategies in a single-phase 6/6 SRM. While the target of the random turn-on/off angle technique is to decrease the amplitude of the fundamental harmonics, the random PWM technique is used to provide harmonic spectra intensity flatter than that obtained by conventional methods. The proposed random technique has been compared with the conventional methods, to analyze their influence on harmonic spectra reduction. The HSF is used to

TABLE III

COMPARISONS OF HSF FOR VARIOUS $\Delta \alpha_{r}$ FOR PROPOSED MEthod

\begin{tabular}{||c|c|c|c|c||}
\hline \hline $\begin{array}{c}\Delta \alpha_{r} \\
\text { [degree] }\end{array}$ & 1 & 2 & 3 & 4 \\
\hline HSF[\%] & 17.13 & 16.29 & 17.07 & 19.01 \\
\hline
\end{tabular}




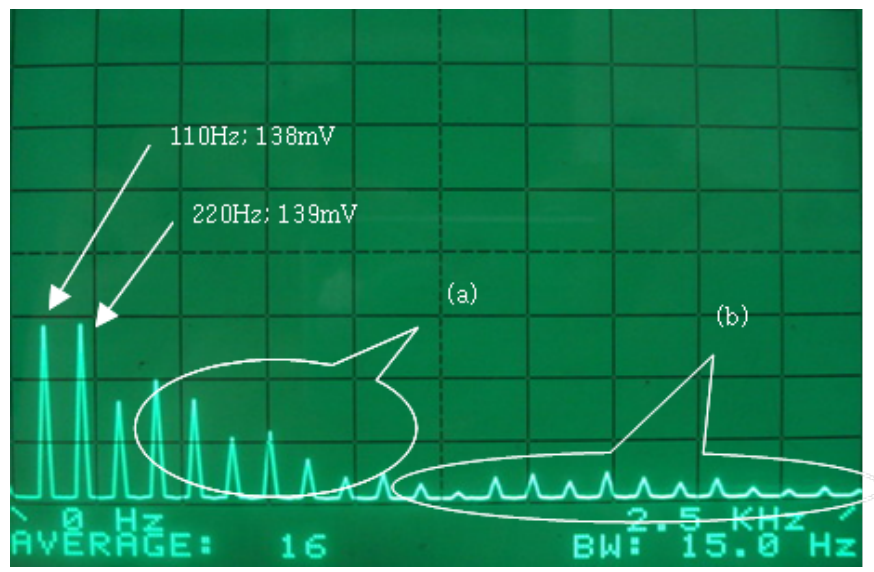

(a) Conventional method with chopping mode $(\mathrm{HSF}=40.03 \%)$

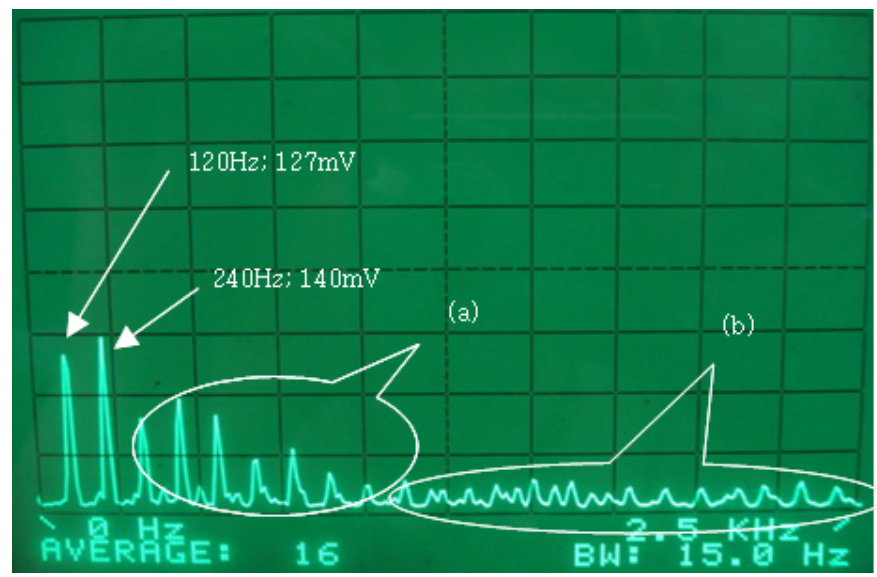

(b) Conventional method with RPWM technique (HSF=18.31\%)

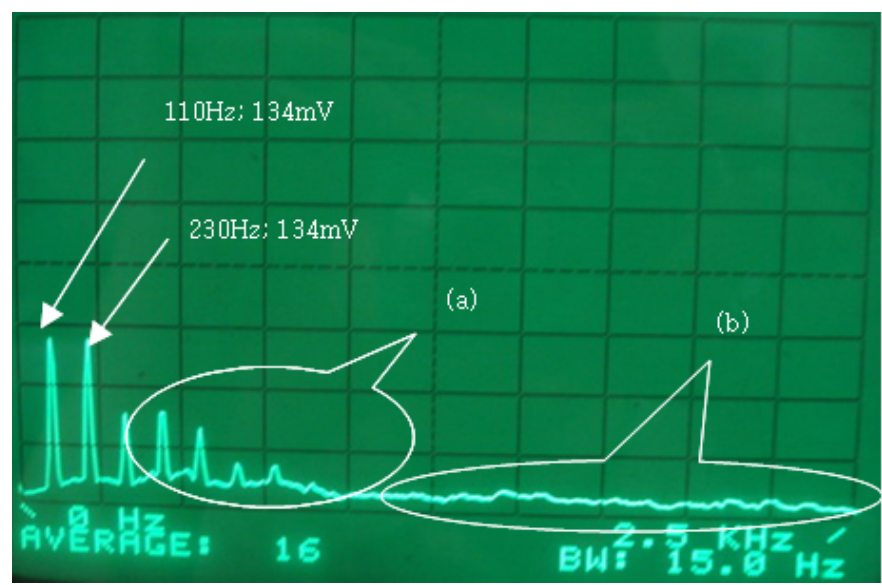

(c) Proposed method $(\mathrm{HSF}=16.29 \%)$

Fig. 11. Measured output voltage spectra. (x-axis: $250 \mathrm{~Hz} /$ div.; y-axis: $50 \mathrm{mv} / \mathrm{div}$.)

evaluate the random PWM technique. The experimental results demonstrate that the new proposed strategy provides better harmonic spectra performance than conventional strategies in spreading the harmonic power over a wide frequency range. This method can be applied for all SRMs including threephase and two-phase SRMs without the modification of certain parameters.

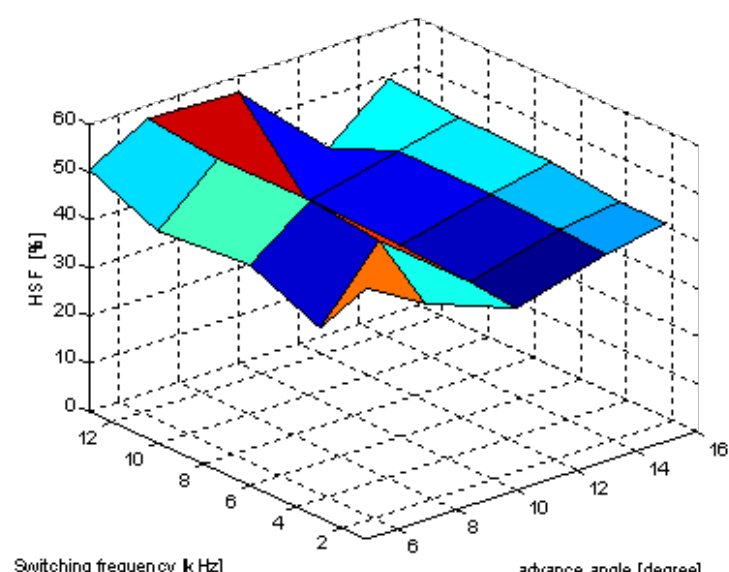

(a) Conventional method with chopping mode

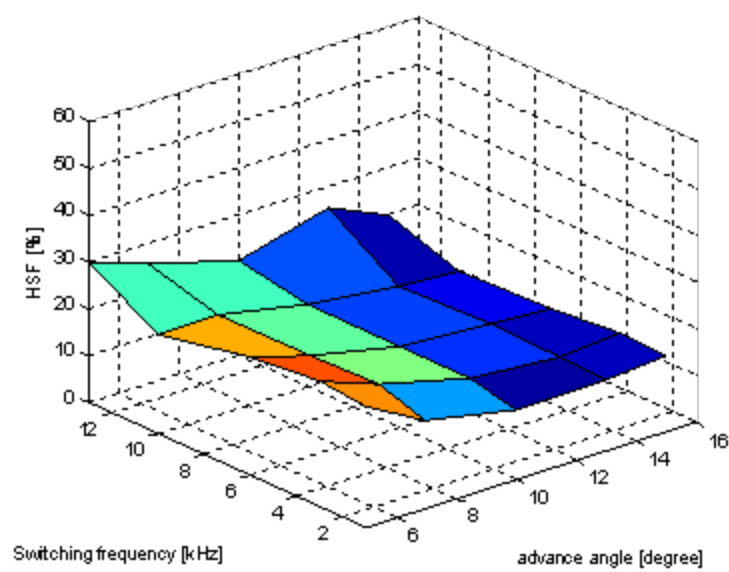

(b) (Conventional method with RPWM technique

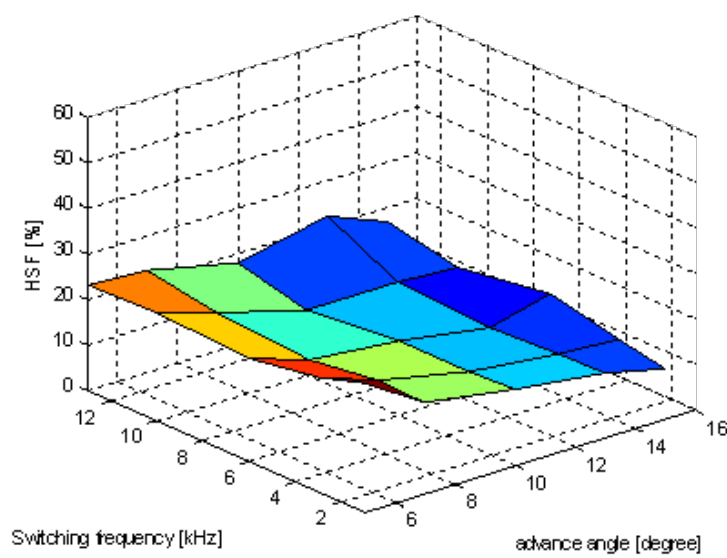

(c) Proposed method

Fig. 12. Voltage spectra for different switching frequency.

\section{ACKNOWLEDGMENT}

This work was supported by a Grant from the Korean Ministry of Education, Science and Technology (The Regional Core Research Program/Biohousing Research Institute), and is in part the outcome of a manpower development program for 
Energy and Resource supported by the Ministry of Knowledge and Economy.

\section{REFERENCES}

[1] R. Krishnan, Switched Reluctance Motor Drivers, CRC Press, 2001.

[2] D. H. Lee, T. H. Kim, and J. W. Ahn, "A hydraulic-oil pump system using SR drive with a direct torque control scheme," Journal of Power Electronics, Vol. 9, No. 3, pp.491-498, 2009.

[3] D. S. Shin, H. Y. Yang, Y. C. Lim, P. Freere, and K. Gurung, "Rotor position sensing method for switched reluctance motors using an indirect sensor," Journal of Power Electronics, Vol. 5, No. 3, pp.173-179, 2005.

[4] D. E. Cameron, J. H. Lang, and S. D. Umans, "The origin and reduction of acoustic noise in doubly salient variable-reluctance motors," IEEE Trans. Ind. Applicat., Vol.28, No.6, pp. 1250-1255, 1992.

[5] F. Blaabjerg and J. K. Pedersen, "Digital implemented random modulation strategies for ac and switched reluctance drives," in Conf. Rec. of IEEE IECON'93, pp.676-682, 1993.

[6] D. H. Lee, T. H. Kim, and J. W. Ahn, "A performance comparison of excitation strategies for a low noise SRM drive," Journal of Power Electronics, Vol. 5, No. 3, pp.218-223, 2005.

[7] H. Chen, C. Zhang and X. Meng, "Variable angle PWM adjustablespeed control for switched reluctance motor drive," EPE-PEMC 2000, pp. 6-209 6-212, 2000.

[8] C. Pollock, and C. Y. Wu, "Acoustic noise cancellation technique for switched reluctance drives," IEEE Trans. Ind. Applicat., Vol. 33, No. 2, pp. 477-484, Mar./Apr. 1997.

[9] B. Fahimi, G. Suresh, K. M. Rahman, and M. Ehsani, "Mitigation of Acoustic Noise and Vibration in Switched Reluctance Motor Drive Using Neural Network Based Current Profiling," in Conf. Rec. IEEE-ISA Annu. Meeting, pp.715-722, 1998.

[10] P. O. Rasmussen, F. Blaabjerg, J. K. Pedersen, P. C. Kjaer, and T. J. E. Miller, "Acoustic noise simulation for switched reluctance motors with audible output," EPE'99, CD-ROM, 1999.

[11] S. Y. Oh, Y. G. Jung, S. H. Yang, and Y. C. Lim, "Harmonic-spectrum spreading effects of two-phase random centered distribution PWM (DZRCD) scheme with dual zero vectors," IEEE Trans. Ind. Electron., Vol. 56, No. 8, pp.3013-3020, Aug. 2009.

[12] K. S. Kim, Y. G. Jung and Y. C. Lim, "A new hybrid random PWM scheme," IEEE Trans. Power Electron., pp.192-200, Jan. 2009.

[13] M. M. Bech, J. K. Pedersen and F. Blaabjerg, "Random modulation techniques with fixed switching frequency for three-phase power converters," IEEE Trans. Power Electron., Vol. 15, No. 4, pp.753-761, 2000.

[14] K. M. Rahman, and S. E. Schulz, "High-performance fully digital switched reluctance motor controller for vehicle propulsion," IEEE Trans. Ind. Applicat., Vol. 38, No. 4, pp.1062-1071, 2002.

[15] F. Blaabjerg, P. C. Kjaer, P. O. Rasmussen, and C. Cossar, "Improved digital current control methods in switched reluctance motor drives," IEEE Trans. Power Electron., Vol. 14, No. 3, pp.-571, 1999.

[16] R. L. Kirlin, M. M. Bech, A. M. Trzynadlowski, B. Huo, "Power and power spectral density in PWM inverters with randomized switching frequency," in Conf. Rec. of IEEE PESC'01, pp. 188-192, 2001.

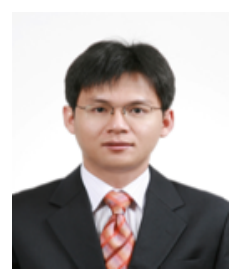

Minh-Khai Nguyen was born in Vietnam in 1982. He received a B.S. degree in Electrical and Electronics Engineering from the Ho Chi Minh University of Technology, Ho Chi Minh City, Vietnam, in 2005, and a M.S. degree in Electrical Engineering from Chonnam National University, Gwangju, Korea, in 2007. He is currently working toward a Ph.D. in Electrical Engineering at Chonnam National University. His current research interests include switched reluctance motor drives, power quality and Z-source converters. He is also a member of the Korean Institute of Power Electronics.

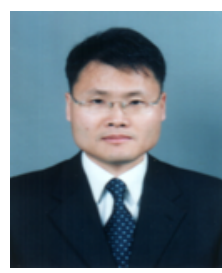

Young-Gook Jung was born in Gwangju, Korea, in 1963. He received his B.S., M.S. and Ph.D. in Electrical Engineering from Chonnam National University in 1982, 1986 and 1996, respectively. He is currently an Associate Professor in the Department of Electrical Engineering, Daebul University, Youngam-Geun, Chonnam, Korea. His research interests are Z-source converters and their applications, random PWM schemes, active power filters, power quality problems and solutions. Dr. Jung has received several Prize Paper Awards from the KIEE and the KIPE of Korea.

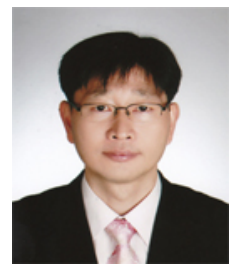

Hyong-Yeol Yang was born in Chonnam, Korea in 1969. He received his B.S. M.S. and Ph.D. in Electrical Engineering from Chonnam National University, Gwangju, Korea in 1993, 1998 and 2004 respectively. His research experience includes work done with Hyundai Motor Company, the Regional Research Center for High-quality Electric Component and Systems at Chonnam National University, Honam University and G-Auto Co., Korea. He has also done visiting research at Virginia Tech., USA. He is currently a full time lecturer in the department of Electrical Engineering at Honam University, Gwangju, Korea. His main research interests are in the areas of fuzzy logic control, design and drives of electric machines, and applications using microcontrollers.

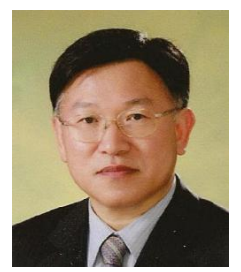

Young-Cheol Lim was born in Chonnam, Korea, in 1953. He received a B.S. degree in Electrical Engineering from Chonnam National University in 1975 . He received his M.S. and Ph.D. from Korea University in 1977 and 1990, respectively. He has been a professor of Chonnam National University since 1981. He was a Director of the Research Center for High-quality Electric Components and Systems in Chonnam National University from 1998 to 2007. His research interests are power electronics, control instruments and neuro-fuzzy control. He is the coauthor of three books and has authored more than 200 published technical papers. He has been the president of KIPE in 2009. He is a Member of the IEEE. He has received a number of awards, including the 2000 KIPE Best Paper Award, and the 2001 KIPE Academic Award. 